\title{
RÁDIO COMUNITÁRIA COMO MECANISMO PARA PARTICIPAÇÃO SOCIAL NO CONTEXTO DA GESTÃO DESCENTRALIZADA DOS SERVIÇOS DE SAÚDE
}

\section{BROADCASTING AS A MECHANISM FOR CONSUMER PARTICIPATION IN THE CONTEXT OF DELIVERY HEALTH CARE}

\author{
Paulo Rogério Gallo" ${ }^{1}$, Márcia de Toledo Blake², Sophia Karlla Almeida Motta-Gallo
}

\begin{abstract}
RESUMO
Objetivo: compreender a percepção de gestores de Unidades de Saúde sobre o uso das rádios comunitárias (RC) como mecanismo para a ampliação da participação e processo de controle social no contexto da gestão descentralizada da saúde. Método: descrição e exploração, com abordagem qualitativa, de recortes discursivos de entrevistas com gestores de municípios brasileiros, analisados em quatro eixos temáticos: (1) RC como ambiente de uso popular; (2) RC como espaço de comunicação e de educação em saúde; (3) concepção sobre o modelo de atenção à saúde; (4) participação social nos serviços de saúde. Resultados: a partir dos modelos de gestão adotados, observa-se tendência ao exercício instrucional de educação em saúde. Proposta que preconiza ações de saúde e intervenção, normativas. Este modelo de atenção e educação se distancia da perspectiva da compreensão da Saúde como produto histórico. O enfoque educativo adotado salienta a importância de ações higienistas de saúde, naturalizando a abordagem sobre os determinantes sociais do processo saúde-doença.
\end{abstract}

Palavras-chave: comunicação em saúde; participação comunitária; assistência à saúde; administração dos serviços de saúde; redes sociais.

\begin{abstract}
Objective: to understand the perception of managers of health units on the use of community radio (CR) as a mechanism for expansion of consumer participation and control process in the context of delivery health care. Method: study with descriptive exploratory design and qualitative approach based on interviews with managers of counties analyzed under four themes: (1) CR environment and popular use, (2) CR as space communication and health education, (3) design on the model of health care, (4) consumer participation in health services. Discussion: from the management models adopted, there is a tendency to exercise a instructional health education. Proposal that uses normative paradigm to health care and intervention. This model of care and education is far from the perspective of understanding of Health as historical product. The educational approach adopted emphasizes the importance of measures of health hygienists, naturalizing approach on the social determinants of healthdisease process.
\end{abstract}

Key words: health communication; consumer participation; delivery of health care. Health services administration; social networks.

1 Departamento de Saúde Materno-infantil da Faculdade de Saúde Pública da Universidade de São Paulo, Brasil. Av. Dr. Arnaldo, 715 - 01246-904 - São Paulo - SP.

2 Laboratório de escrita científica da Faculdade de Medicina do ABC.

Correspondência para: prgallo@usp.br e sophiamottagallo@usp.

Pesquisa com financiamento: edital CNPq 23/2006 - Processo no 409441/2006-6

Como citar este artigo: Gallo PR, Motta-Gallo SKA. Broadcasting as a mechanism for consumer participation in the context of delivery health care. Journal of Human Growth and Development 2011; 21(3): 841-848.

Artigo submetido em 12.12.10, aceito em 10.08.11. 


\section{INTRODUÇÃO}

Como desafio contemporâneo dos Sistemas Nacionais de Saúde está o de compatibilizar os preceitos da promoção da saúde ${ }^{1}$, fundamentalmente estruturada no desenvolvimento da autonomia das comunidades aos preceitos da medicina preventiva, desenvolvida a partir da teoria dos riscos populacionais ${ }^{2,3}$.

Base da epidemiologia tradicional, a teoria dos riscos populacionais substancia os Modelos Nacionais de Saúde na chamada relação custo/benefício ou custo/efetividade ${ }^{4,5}$. Essa lógica estabelece prioridades de investimento ao preconizar políticas públicas de saúde sem diálogo com as expectativas de participação da comunidade em relação a seus cuidados de saúde ${ }^{6,7}$.

Desse modo, surgem questionamentos quanto ao impacto dos modelos políticos estruturados nos Sistemas Nacionais de Saúde em estimular a equidade social no acesso da população aos serviços de saúde ${ }^{8-12}$. Particularmente, nos modelos assistenciais de gestão descentralizada atentos à perspectiva da equidade, a diversidade cultural e a tradição histórico-social das populações deveriam estar contempladas e baseadas nos princípios da promoção de saúde ${ }^{11}$.

Sob esse ponto de vista, mais do que uma distribuição espacial de bens e serviços, as propostas descentralizadas com acesso universal e/ou equitativo conduzem à revisão e discussão sobre a construção da cidadania e sua relação com o Estado. Questão que extrapola a realidade brasileira e encontra ressonância em projetos políticos de outros países e remete a evolução das propostas de saúde coletiva em países de economia liberal e neoliberal ${ }^{13}$, nos quais é possível perceber as reestruturações do aparato estatal e reordenação das relações Estado-sociedade ${ }^{13-15}$.

Paradoxalmente, independentemente da política de saúde, os paises com vocação neoliberal convivem com o encolhimento do espaço público na administração de outros setores sociais, como educação, cultura, lazer, segurança, saneamento, habitação ${ }^{14,16}$.
Cabe destacar o Sistema Único de Saúde brasileiro (SUS) que propõe compatibilizar necessidades e expectativas da comunidade às possibilidades concretas do Sistema que objetivamente opera com limitações de recursos humanos, materiais, tecnológicos e financei$\operatorname{ros}^{17}$, mas que por seus princípios paradigmáticos propõe a Equidade, Universalidade e Integralidade ${ }^{18-20}$ da assistência à Saúde, esta em seu significado contemporâneo ${ }^{15}$.

Assim sendo, tendo em vista a perspectiva de ampliar a participação social, em acordo com o conceito positivo de saúde ${ }^{21}$, o planejamento e a execução das políticas de saúde devem incorporar entre as diretrizes da gestão descentralizada da saúde ${ }^{20,21}$ os valores sociais e culturais das comunidades ${ }^{22}$.

Nesse sentido, a rádio comunitária (no Brasil, há mais de 3500 dessas emissoras de pequena potência, autorizadas pelo Ministério das Comunicações), como veículo de comunicação em massa, pode funcionar como elemento de interlocução e interatividade ${ }^{23}$. Um sistema de mediação entre gestores públicos e a população circunscrita na sua área de abrangência.

Isso posto, partimos do suposto de que as rádios comunitárias podem se tornar um mecanismo básico dentro dos processos de participação de comunidades no SUS ${ }^{7,23,24}$. Desse modo, por ser não só um veículo de transmissão, mas uma estratégia de/para mudança cultural em sociedades complexas ${ }^{22}$, a utilização desses equipamentos no contexto da gestão descentralizada dos serviços de saúde pode contribuir com ampliação do exercício do controle social na gestão ao: a) funcionar como elemento de mediação entre gestores de saúde e população e b) garantir a advocacia de direitos sociais e melhoria das condições de vida e saúde da população.

Assim, o objetivo é compreender a percepção de gestores de Unidades de Saúde sobre o uso das rádios comunitárias (RC) como mecanismo para a ampliação da participação e processo de controle social no contexto da gestão descentralizada da saúde. 


\section{MÉTODO}

Estudo exploratório de caráter descritivo, que utiliza a abordagem qualitativa e tem como referência recortes discursivos de entrevistas com gestores de Unidades Básicas de Saúde (UBS) e Estratégia de Saúde da Família (ESF), em municípios brasileiros. O estudo foi aprovado pelo Comitê de Ética em Pesquisa da Faculdade de Saúde Pública da Universidade de São Paulo (FSP/USP), em 2006.

A escolha da base territorial para a pesquisa justifica-se pelas características: a) ser cidade dormitório; b) ser polo de atração de famílias migrantes, particularmente, as das regiões norte e nordeste do país; e c) possuir rádio comunitária ciente de suas possibilidades de parceria com o SUS.

Os resultados e discussão estão organizados em quatro eixos temáticos, em acordo com o roteiro das entrevistas, a saber: (1) rádios comunitárias como ambiente de uso popular; (2) rádios comunitárias como espaço de comunicação e de educação em saúde; (3) concepção sobre o modelo de atenção à saúde; (4) participação social no contexto da gestão descentralizada dos serviços de saúde.

\section{RESULTADOS E DISCUSSÃO}

Podem-se perceber, nos eixos temáticos apontados, dificuldades de alguns gestores acolherem, no contexto da cultura institucional, processos e recursos populares que advoguem direitos sociais da população.

\section{(1) Rádios comunitárias como um ambiente de uso popular}

Os informantes-chave generalizam considerações sobre a programação da rádio ora com um viés de produtos sem criatividade e de maneira enfadonha, ora como frutos de sensacionalismo.

"Eu acho que é interessante eu acho legal (...) Acho que tem momento certo. Hora certa. Para não torná chato (...) sabê faze o negócio(...) prendê a atenção, mas acho que dá. Porque as rádios que vão ser feitas aqui são pessoas da comunidade. Então dá prá fazer, mas o que a gente vê são críticas em momentos inoportunos ou sem um esclarecimento de como o Sistema funciona" [Discurso de informante-chave 01]

Neste sentido, observa-se, na percepção deles, uma tendência dos ouvintes optarem pelo entretenimento musical em detrimento de informações de interesse público que eventualmente a rádio possa estar veiculando.

"(...) Acho ela [a rádio comunitária] importante na medida em que veicula as informações nos dois sentidos. Tanto da instituição para a população como da população para a instituição. Não deixa de ser um canal de comunicação importante para disseminar opiniões, única coisa que eu receio (...) é não cair no sensacionalismo. " [Discurso de informante-chave 03]

De qualquer maneira, os discursos atribuem juízos negativos de valor sobre ações comunicativas criadas e/ou gerenciadas em ambiente popular.

\section{(2) Rádios comunitárias como espaço de comunicação e de educação em saúde}

Robert Putnam ${ }^{25}$ atribui à comunicação comunitária o papel estratégico para o desenvolvimento da cidadania. No cenário montado por Putnam, a comunicação desponta como um elemento integrador de experiências e iniciativas da comunidade, base do senso de solidariedade social e da participação social e política.

Um aspecto importante nessa questão, apontada como central entre os educadores contemporâneos, ainda não percebida pelos informantes-chave em tela, é a valorização dos componentes histórico-sociais e culturais e vida associativa como integrantes dos processos educativos.

"(...) eu acho assim, que é de grande interesse né!, da saúde em ter a rádio como meio de comunicação. Se não temos uma televisão que é o que uma pessoa quer, o visual, tudo... a rádio é 
um outro serviço que é muito importante, eu acho o pessoal da saúde tem que ter um momento aí. (...)" [Discurso de informante-chave 01]

Nesse contexto, a rádio é percebida como meio de comunicação capaz de "noticiar informações de saúde e/ou doença". Isso posto, percebe-se que o processo educativo é compreendido como falar de doenças e não se nota, nos discursos, a preocupação em ajustar a ação comunicativa às características culturais da população.

"(...) Por que não utilizar a rádio para falar das doenças e dos meios de prevenção? Olha: a dengue existe, a frequência é esta! É um meio de comunicação que tem que existir, vai nos ajudar né!" [Discurso de informante-chave 02]

Deve-se apontar também ainda o distanciamento, na percepção dos gestores, do princípio de transdução cultural. Ou seja, a minimização da valorização, no processo educativo, de comunicadores locais, capazes de levar na linguagem de seu grupo as informações de saúde indicadas como necessárias pelos profissionais de saúde.

\section{(3) Concepção sobre o modelo de atenção à saúde}

Com relação ao modelo adotado, observa-se na fala dos gestores, a tendência ao exercício tradicional (instrucional ou formal) de educação em saúde. Proposta que compreende e preconiza ações de saúde na lógica de modelos de intervenção tradicionais.

Este modelo de atenção se afasta da perspectiva da conceituação da Saúde como produto histórico. O enfoque educativo adotado pelos gerentes salienta a importância das ações higienistas de saúde, naturalizando as ideias sobre os determinantes sociais envolvidos no processo saúde-doença.

"Eu acho que saúde para todos é prevenir as doenças (...) Como eu acabei de falar a última palavra. Prevenção. Eu acho que saúde para todos é prevenir as doenças. O saudável é prevenção das doenças. É a minha compreensão geral (...)Eu acho que é a coisa mais objetiva para manter a saúde é a prevenção" [Discurso de informante-chave 01]

Observa-se no discurso do informante-chave 01 que não há um diálogo com o preceito da Organização Mundial da Saúde sobre a concepção do processo saúde-doença ${ }^{5}$. Há, contudo, o conceito expresso de que prevenção é sinônimo de saúde, reduzindo as dimensões de cidadania e participação social. Além da dificuldade de uma reflexão sobre a complexidade que o tema suscita na interface com os determinantes sociais da saúde.

É interessante também observar que as bases da reforma do Sistema de Saúde estariam em contraste a esse modelo, uma vez que Sistemas Nacionais, que se propõe a ter como princípio a promoção da saúde, devem reconhecer que saúde depende dos acessos à educação, transporte, moradia, alimentação, segurança, trabalho, lazer dentre outras. Necessidades humanas de responsabilidade coletiva - como a rede de fatores sociais que conotam saúde como bem coletivo.

"(...) A saúde, hã, uma condição que depende de vários fatores como o próprio..., a saúde física, o meio interferindo na saúde, então teria a questão do saneamento, educação, informação, fator econômico que é uma coisa bem mais ampla" [Discurso de informante-chave 02]

Contudo, como se evidencia nos discursos, apesar do compromisso do SUS na compreensão e enfrentamento dos determinantes sociais da saúde, 0 modelo de atenção estrutura-se a partir de modelos educativos individualizados e voltados a uma abordagem centralizada na figura dos agentes de saúde, perdendo-se oportunidades de estimular processos de ação coletivas ${ }^{26}$.

"(...) Bom, então, é através dos nossos agentes de saúde, é através do tête a tête dos auxiliares, é também das doutoras e dos doutores falarem sobre a rotina e o eventual né!(...). É o que eu falo, a cada momento é feito pelos nossos agentes da saúde saindo da UBS, (...) o trabalho nosso frente à comunidade né!, e fazer a educação." [Discurso de informante-chave 03] 
Opinião que legitima a ausência de um protagonismo coletivo nas/das ações de educação e saúde, em prol do fortalecimento do controle social no SUS, haja vista a centralização de todo processo educativo na figura dos agentes de saúde.

\section{(4) Participação social no contexto da gestão descentralizada dos serviços de saúde}

Os gestores, segundo depoimentos, organizam suas observações ao redor de uma deficiência quanto ao processo participativo. A participação desejável é vista como uma atividade mais consistente. $\mathrm{O}$ que se observa como produto da participação são críticas pontuais e extemporâneas ao SUS ${ }^{27}$.

"(...) a participação social ainda é pequena por parte de todos.... Talvez porque nós venhamos de um momento histórico de repressão. Ou seja, são pessoas que tiveram a adolescência, a juventude na época da ditadura. Acho que isto tem a ver com esta inatividade embora todos sejam chamados, as pessoas ainda não têm esta cultura" [Discurso de informante-chave 01].

Vale destacar, no discurso do informante-chave, a tentativa de trazer um nível explicativo ao déficit participativo, que seria resultado de duas possibilidades: a) uma cultura de passividade herdada de condições políticas pregressas excludentes e repressivas e b) baixo empoderamento da população.

"Deveria ser mais efetiva [a participação da comunidade]. Deixa a desejar, (...) o próprio conselho municipal é uma instituição válida, mas não valorizada, pelo menos aqui no município, não sei nos outros. Talvez a população não tenha claro ainda o canal apropriado para fazer as reclamações e reivindicações e discutir as questões(...)"[Discurso de informante-chave 02].

Apesar disso, os discursos não evidenciam quaisquer considerações quanto ao papel gestor junto à população. Antes, referem-se à comunidade como objeto externo ao Serviço de Saúde, ainda que pontuem a existência do ConseIho Municipal de Saúde como órgão legítimo do exercício do controle social no
SUS ${ }^{27,28}$. Entretanto, ao não se perceber como parte da comunidade, homologa a visão distanciada que separa os interesses dos usuários dos serviços de saúde.

Assim, de maneira geral, os resultados encontrados expressam baixa compreensão dos gestores em perceber a rádio comunitária como espaço favorável para o exercício do controle social e participação cidadã, em contextos descentralizados de gestão pública de saúde.

Deve-se evidenciar, neste estudo, que o gestor municipal ao adotar-se como modelo de atenção à saúde a perspectiva tradicional, de caráter biomédicoprevencionista, rompe a possibilidade dialógica preconizada pelos paradigmas da gestão pública pactuada com a população. Nesse modelo, surge o risco de transformar o processo de gestão num referendum dos determinantes da doença e, nesse sentido, abrir a possibilidade de transferir à população a responsabilidade pelas más condições de vida ${ }^{23}$.

Estimula-se, ao se naturalizar as condições de saúde, a descontextualizarão do processo saúde-doença do macro modelo econômico-social e, portanto, dos determinantes sociais.

Desse modo, despolitiza-se não apenas as comissões paritárias das várias esferas de gestão do SUS, criadas com a finalidade de dar transparência às ações administrativas, mas também se colabora para a despolitização das relações intersetoriais da área da saúde ${ }^{22,27}$

Vale ressaltar que urge não delimitar os esforços da reforma a um ajuste técnico-administrativo do Sistema de saúde vigente, mas de levar uma real modificação na forma de conceber o papel do Estado nesse processo.

No contexto da reforma sanitária brasileira, palco desta pesquisa, emergem duas questões relevantes e imbricadas. Por um lado, como conquistar a população para o exercício do controle social nas diversas esferas do SUS, conscientizá-la de seus direitos constitucionais e educá-la para o uso dos equipamentos da saúde, se a práxis dos dirigentes está reduzida ao componente técnico e não incorpora a dimensão social e política da saúde? Por outro, como 
tratar esta questão de forma equitativa, ou seja, equalizar os esforços de gestão do SUS para dar vez e voz àqueles que não se reconhecem como sujeitos do processo de construção do SUS?

Isso posto, fica o questionamento de como será possível empoderar a população para que compreenda e assuma seu papel protagonista e não de conformá-la apenas como "beneficiária" do SUS. O desafio contemporâneo vai além do aperfeiçoamento técnico-instrumental e gerencial do Sistema de Saúde. Ou seja, o desafio transcende a abordagem administrativa da assistência médica (seja na ótica preventiva ou na curativa) das equipes locais de saúde para o campo da construção de uma sociedade democrática, diretriz sine qua non do SUS.

Alvarez e col. ${ }^{22}$ nos remetem, na América Latina, ao autoritarismo social para descrever o conjunto das relações sociais que presidem a hierarquia social discricionária. Ressaltam a necessidade de mobilizar e repolitizar o debate sobre o direito à saúde, na perspectiva da ampliação da participação e do poder de intervenção, dos grupos sociais excluídos.

Segundo as autoras, por detrás da postura instrucional e assimétrica do relacionamento entre serviços e população, emerge um cunho individualista evidenciado em sociedades com desigualdade de classes $^{22}$.

No que pode tanger à importância do controle social para o SUS, as ideias de Putnam, Alvarez e col. nos alertam para a necessidade de expansão dos princípios de participação e controle democrático da gestão - conforme expectativas e preceitos da reforma sanitária contudo também fazem ressalvas quanto às possibilidades concretas de participação social em nosso país ${ }^{27,22}$.

Segundo Costa e Lionço ${ }^{29}$, os princípios políticos do SUS (Equidade, Universalidade e Integralidade) devem ser compreendidos como

"elementos interpeladores para as políticas de saúde, que por sua vez devem diante das imposições, potencialidades e especificidades das circunstâncias históricas, serem realocados como questões a serem trabalhadas em cada comunidade pelos gestores e trabalhadores do sistema" 29

De acordo com Castiel ${ }^{1}$, Viana, Lima e Oliveira ${ }^{10}$ e Santana ${ }^{12}$, os ajustes do legado ideo-político neoliberal preconizam nas entrelinhas sob a égide da equidade como princípio de justiça social a busca da focalização do Sistema aos mais pobres, rompendo a universalidade preconizada no SUS ${ }^{19,20,27}$. Esse legado pode contribuir para a fragmentação de projetos sociais de interesse coletivo no Brasil, como é o caso das discussões protagonizadas pelos gestores no campo dos pactos de gestão ${ }^{25}$.

Corrobora esta abordagem, a agenda de financiamento de pesquisas e estudos em Ciência \& Tecnologia no Brasil, pois apresenta forte interesse na caracterização das condições sociais e sua relação com estados de saúde de grupos populacionais específicos ${ }^{26}$.

Contudo deve-se notar que a saúde não é meramente um serviço passível de uma agenda que preconiza os princípios da justiça distributiva como parâmetros de avaliação e implementação de ações, serviços e pesquisas nas áreas sociais e da saúde.

Nesse sentido, ferem-se tanto os princípios da Declaração Universal dos Direitos Humanos como os preceitos Constitucionais brasileiros, segundo os quais a saúde é, antes de tudo, um direito universal assentado em princípios juridicamente indivisíveis e intangíveis que tomam a vida como valor supremo e não fruto de agendas técnico-jurídicas nem político-partidárias 5,16,20,21,28

Assim sendo, o uso da rádio comunitária como espaço dedicado às questões de saúde pode servir como instrumento de advocacia de direitos humanos e sociais, bem como ferramenta de gestão a partir da perspectiva da interatividade com a população. Apesar da experiência brasileira ainda não apontar nesta direção.

No Brasil, a mídia das rádios comerciais vem fazendo esforço para caracterizar as rádios comunitárias como socialmente perigosas ${ }^{23}$. Neste contexto, a Saúde Pública deve abrir um espaço 
de interlocução para problematizar questões complexas, como é o exemplo das rádios comunitárias como espaço coletivo, democrático e descentralizado. Ou seja, espaços potencialmente favoráveis para desenvolver ações loco-regionais de promoção de saúde e fomento da participação comunitária nos processos de tomada de decisão com relação à saúde individual e coletiva?.

Desta maneira, os gestores de saúde não se mostram sintonizados com a perspectiva política e interdisciplinar que a diretriz da participação social prescinde.

\section{REFERÊNCIAS}

1. Castiel LD. Insegurança, ética e comunicação em saúde pública. Rev. Saude Publica. 2003 Abr; 37(2): 161167.

2. Debatedores. Cienc saude coletiva. 2001 Sep ; 6(1): 20-47.

3. Ramos LR. Grupos de promoção à saúde no desenvolvimento da autonomia, condições de vida e saúde. Rev Saude Publica. 2006;40(2):34652.

4. Freitas CM. Avaliação de riscos como ferramenta para a vigilância ambiental em Saúde. Inf Epidemiol SUS. 2002 Dez; 11(4): 227-239.

5. World Health Organization. IPCS risk assessment terminology. Harmonization Project Document n. 1. Geneva: WHO; 2004.

6. Silvério MR, Patrício ZM. O processo qualitativo de pesquisa mediando a transformação da realidade: uma contribuição para o trabalho de equipe em educação em saúde. Cienc saude coletiva. 2007 Mar ; 12(1): 239-246.

7. Gallo PR, Espírito Santo SKAM. A percepção de gestores de saúde sobre a rádio comunitária como instância mediadora para o exercício do controle social do SUS. Saúde em Debate. 2009 maio/ago; 33(82): 240-251.

8. Fleury S. Iniquidades nas políticas de saúde: o caso da América latina. Rev Saúde Pública. 1995; 29(3): 243-50.
De modo geral, o projeto de aproximação com a população, defendido pelos entrevistados, mostrou-se tradicional no tocante aos propósitos e aos instrumentos rotineiros de comunicação. Em todos os casos a responsabilidade dos serviços de saúde foi compreendida como cuidar das doenças.

Essas constatações realçam a gerência dos Serviços de Saúde e sua restrita compreensão sobre o processo saúde-doença, bem como o uso de mídias alternativas, desafios para a efetivação do SUS.

9. Titelman D. Reformas al Sistema de Salud: Desafios pendientes. CEPAL, série financiamento del desarrollo, 104. Santiago de Chile: Publicación de las Naciones Unidas; 2000.

10. Almeida C. Equidade e reforma setorial na america latina: um debate necessário. Cad Saúde Pública. 2002; 18 suplemento 1: 23-36.

11. Magalhães R, Burlandy L, Senna MCM. Desigualdades sociais, saúde e bem-estar: oportunidades e problemas no horizonte de políticas públicas transversais. Ciênc saúde coletiva. 2007 Dez; 12(6): 1415-1421.

12. Duarte CMR. Equidade na legislação: um princípio do sistema de saúde brasileiro? Ciênc Saúde Coletiva. $2000 ; 5(2): 443-463$.

13. Santana JP. História, saúde e seus trabalhadores: o contexto internacional e a construção da agenda brasileira. Cienc saude coletiva. 2008 mai/jun; 13(3): 832-835.

14. Moraes RC. Reformas neoliberais e políticas públicas: hegemonia ideológica e redifinição das relações estado-sociedade. Educ Soc. 2002 set; 23(80): 13-24.

15. Almeida CM. Reforma do Estado e reforma de sistemas de saúde: experiências internacionais e tendências de mudança. Cienc saude coletiva. 1999; 4(2):263-286.

16. Magalhaes R. Integração, exclusão e solidariedade no debate contemporâneo sobre as políticas sociais. Cad Saúde Pública. 2001 mai-jun;17(3): 569-79. 
17. Wendhausen A, Cardoso SM. Processo decisório e Conselhos Gestores de Saúde: aproximações teóricas. Rev bras enferm. 2007; 60(5):579-84.

18. Pasche DF. A reforma necessária do SUS: inovações para a sustentabilidade da política pública de saúde. Ciênc saúde coletiva. 2007 Apr ; 12(2): 312-314.

19. Czeresnia D. Ciência, técnica e cultura: relações entre risco e práticas de saúde. Cad. Saúde Pública . 2004;20(2):447-55.

20. Marsiglia RMG, Silveira C, Carneiro Junior N. Políticas sociais: desigualdade, universalidade e focalização na saúde no Brasil. Saude soc. 2005; 14(2): 69-76.

21. Casa Civil. Lei n. 8080 de 19 de setembro de 1990. Dispõe sobre as condições para a promoção, proteção e recuperação da saúde, a organização e o funcionamento correspondentes e dá outras providências. Disponível em: http:// www.planalto.gov.br/ccivil_03/Leis/ L8080.htm. Obtido em: 06 out 2009.

22. Alvarez SE, Dagnino E, Escobar A. Cultura e política nos movimentos sociais latino-americanos. Belo Horizonte: Editora da UFMG; 2000.

23. Gallo PR. Radiodifusão comunitária: um recurso a ser valorizado no âmbito da educação em saúde. Saúde em Debate. 2001; 25(59):59-66.
24. Costa MSR. Rádios comunitárias como rádios educativas, explorando os potenciais educativos do rádio e das rádios comunitárias, na Baixada Fluminense / Rio de Janeiro. In: Anais do XXIV Congresso Brasileiro de Ciências da Comunicação; 2001 Set; Campo Grande (MS). São Paulo: Intercom; 2001. Disponível em: http:/ /reposcom.portcom.intercom.org.br/ dspace/handle/1904/4917. Acesso em: 05 out 2009.

25. Putnam RD. Comunidade e democracia: a experiência da Itália moderna. 3. ed. São Paulo: Editora da Fundação Getulio Vargas; 2003.

26. REIS EP. Desigualdade e solidariedade: uma releitura do "familismo amoral" de Banfield. Rev Bras Ciênc Soc 1995;10(29):35-48.

27. Ministério da Saúde. Decreto no. 99.438, de 7 de agosto de 1990 que dispõe sobre a composição dos Conselhos de Saúde. Disponível em: http://conselho.saude.gov.br/legislacao/dec99438_070890.htm. Acesso em 06 out 2009.

28. Ribeiro JM. Conselhos de saúde, comissões intergestores e grupos de interesses no Sistema Único de Saúde (SUS). Cad Saúde Pública. 1997 Jan; 13(1): 81-92.

29. Costa AM, Lionço T. Democracia e gestão participativa: uma estratégia para a equidade em saúde. Saúde Soc $2006 ; 15: 34-46$. 